\title{
Gangguan Tidur pada Anak dengan Epilepsi dan Faktor yang Memengaruhi
}

Riona Sari, Agung Triono, Retno Sutomo

Departemen Ilmu Kesehatan Anak Fakultas Kedokteran Universitas Gadjah Mada/RSUP Dr. Sardjito, Yogyakarta

Latar belakang. Gangguan tidur merupakan salah satu komorbid yang sering dijumpai pada anak dengan epilepsi. Sampai saat ini data mengenai hal tersebut masih sangat terbatas.

Tujuan. Mengetahui prevalensi dan faktor yang memengaruhi gangguan tidur pada anak dengan epilepsi.

Metode. Penelitian observasional analitik dengan desain potong lintang pada anak usia 3-18 tahun, yang telah didiagnosis epilepsi minimal 6 bulan. Pasien dengan palsi serebral, diabetes melitus, penyakit jantung, asma, hipertrofi adenotonsil dan anak dengan epilepsi yang telah bebas kejang lebih dari satu tahun dieksklusi dari penelitian. Subyek dipilih secara konsekutif selama periode November 2016 - Maret 2017 di Poliklinik Neurologi Anak RSUP Dr. Sardjito. Gangguan tidur dinilai dengan kuesioner sleep disturbance scale for children (SDSC).

Hasil. Di antara 93 subyek, 63 (67,7\%) mengalami gangguan tidur, terbanyak (63,2\%) adalah gangguan memulai dan mempertahankan tidur. Tipe kejang umum, onset epilepsi kurang dari 3 tahun, monoterapi dan obat anti epilepsi fenobarbital paling sering mengalami gangguan tidur. Akan tetapi, hanya tipe kejang umum yang berhubungan dengan gangguan tidur (OR 5,2, IK95\% 1,35-9,96, p=0,016).

Kesimpulan. Prevalensi gangguan tidur pada anak dengan epilepsi sangat tinggi, terbanyak gangguan memulai dan mempertahankan tidur dan berhubungan dengan tipe kejang umum. Sari Pediatri 2017;19(1):7-13

Kata kunci: gangguan tidur, anak, epilepsi, SDSC

\section{Sleep Disorder and Associated Factors in Children with Epilepsy}

\author{
Riona Sari, Agung Triono, Retno Sutomo
}

Background. Sleep disorder has been associated with chidhood epilepsy. However, there is limited study about this comorbidity. Objective. To investigate prevalence and factors ascociated with sleep disorder in children with epilepsy.

Methods. We conducted a cross sectional analytical study in children aged 3 through 18 years old who has been diagnosed as having epilepsy for at least 6 month. Subjects with cerebral palsy, diabetes mellitus, asthma, heart problem and those who had no seizure for more than one year without anti-epileptic drug were excluded from this study. The subjects were recruited consecutively during period of November 2016 to March 2017 at pediatric outpatient clinic of Dr. Sardjito Hospital. The sleep disorder was evaluated using sleep disturbance scale for children (SDSC) questionnaires.

Results. Among 93 subjects, 63(67,7\%) had sleep disorder, mostly (63,2\%) the disturbance to intiate and maintain sleep. Sleep disorder was more prevalent in general seizure, onset epilepsy less than 3 years, those who received monotheraphy and phenobarbital. Nevertheless, only general seizure is significantly associated with the sleep disorder (OR 5,2, 95\% CI 1,35-9,96, p=0,016).

Conclusion. Sleep disorder is high prevalence in children with epilepsy, mostly difficulty of initiating and maintaining sleep and it is associated with the type of general seizure. Sari Pediatri 2017;19(1):7-13

Keywords: sleep disorder, children with epilepsy, SDSC

Alamat korespondensi: dr. Riona Sari, Departemen Ilmu Kesehatan Anak, Fakultas Kedokteran Universitas Gadjah Mada/RSUP Dr. Sardjito, Jl. Kesehatan No.1 Sekip Yogyakarta 55284. E-mail: rionasari1983@gmail.com 
D uapuluh lima persen gangguan tidur dijumpai pada populasi anak yang sehat, $1 \%-5 \%$ di antaranya adalah gangguan kesulitan bernapas saat tidur (obstructive sleep apneu syndrome: OSAS). ${ }^{1}$ Prevalensi gangguan tidur semakin meningkat pada anak dengan penyakit kronis, seperti asma, epilepsi, diabetes, penyakit jantung bawaan, dan gangguan neuropsikiatri lainnya. ${ }^{2}$

Epilepsi merupakan salah satu gangguan neurologi yang paling sering dijumpai. Berdasarkan data WHO tahun 2005 diperkirakan hampir 45 juta orang terdiagnosis epilepsi, 10,5 juta di seluruh dunia, di antaranya terjadi pada anak di bawah usia 15 tahun atau $25 \%$ dari populasi epilepsi global. ${ }^{3}$ Epilepsi menyumbang $1 \%$ dari seluruh beban penyakit di dunia. Setiap tahunnya, rata-rata terdapat 24-53 kasus baru setiap 100.000 penduduk. ${ }^{4}$ Prevalensi epilepsi di negara maju 30-50 kasus per 100.000 penduduk, sedangkan prevalensi ini meningkat dua kali di negara miskin dan berkembang. ${ }^{5}$

Epilepsi merupakan kelainan neurologis yang sering mempunyai komorbid neurobehavioral terkait dengan masalah psikiatri, kognitif maupun sosial. Gangguan tidur sering terjadi pada pasien epilepsi. ${ }^{1,6,7}$ Jenis kejang, usia awitan terjadinya kejang dan obat anti epilepsi merupakan faktor yang berpengaruh pada gangguan pola tidur dan penurunan kualitas tidur. Sebaliknya, gangguan tidur juga dapat menurunkan ambang kejang sehingga terjadi gangguan kontrol kejang. ${ }^{8}$ Obat anti epilepsi (OAE) yang dilaporkan dapat menyebabkan gangguan tidur, seperti barbiturat, benzodiazepin, fenitoin, asam valproat, gabapentin, karbamazepin dan obat antiepilepsi lainnya menyebabkan gangguan tidur dengan efek yang berbeda-beda. Jumlah obat antiepilepsi, baik yang diberikan monoterapi maupun politerapi, menyebabkan gangguan tidur pada anak dengan epilepsi. ${ }^{9-11}$ Faktor lain yang memengaruhi, yaitu psikososial, budaya, kebiasaan dalam keluarga, lingkungan, co-sleeping, dan sleep hygiene. ${ }^{1,12,13}$

Gangguan tidur dapat ditegakkan dengan baku emas polisomnografi, tetapi alat tersebut mahal sehingga tidak semua tersedia di tempat pelayanan kesehatan. Kuesioner sleep disturbance scale for children (SDSC) yang telah diterjemahkan dalam bahasa Indonesia merupakan salah satu alat skrining yang mudah dan murah. Penilaian validitas dan reliabilitas kuesioner SDSC memiliki sensitifitas 71,4\% dan spesifitas $54,5 \% .{ }^{14}$ Kuesioner SDSC berisi laporan orang tua mengenai pola tidur anak dalam kurun waktu 6 bulan terakhir. Anak yang dinyatakan mengalami gangguan, bila skor total lebih dari 39. Penilaian jenis gangguan tidur berdasarkan komponen pertanyaan dalam kuesioner tersebut. Berdasarkan kuesioner SDSC terdapat 6 jenis gangguan tidur, yaitu memulai dan mempertahankan tidur, pernapasan saat tidur, kesadaran, transisi tidur-bangun, somnolen berlebiihan, dan hiperhidrosis saat tidur.

Berbagai hasil penelitian mengenai hubungan jenis kejang, onset epilepsi, jumlah dan jenis obat antiepilepsi masih kontradiktif dan diagnosis mengenai gangguan tidur masih sering diabaikan. Skrining awal adanya gangguan tidur pada anak dengan epilepsi dapat membantu tata laksana pasien secara komprehensif sehingga kualitas hidup meningkat. ${ }^{15,16}$ Hingga saat ini belum ada penelitian gangguan tidur pada anak dengan epilepsi di Indonesia.

Penelitian ini bertujuan untuk mengetahui prevalensi gangguan tidur dan faktor yang memengaruhi pada anak dengan epilepsi. Diharapkan, kewaspadaan tenaga medis dapat ditingkatkan untuk memberikan edukasi dan pengambilan keputusan terapi yang akan diberikan. Dengan demikian, kualitas hidup anak dengan epilepsi akan meningkat dengan tata laksana secara komprehensif.

\section{Metode}

Penelitian observasional analitik dengan desain potong lintang, digunakan data primer dari kuesioner SDSC dalam kurun waktu 6 bulan (November 2016-Maret 2017). Prosedur penelitian ini telah mendapat izin dan rekomendasi dari Komite Etik Penelitian.

Subyek penelitian adalah anak berusia 3-18 tahun yang terdiagnosis epilepsi minimal 6 bulan berdasarkan klasifikasi ILAE 1989 yang berobat di Poliklinik Neurologi anak RSUP Dr. Sardjito, dalam terapi obat antiepilepsi, dan orangtua yang bersedia diikutsertakan dalam penelitian. Kriteria eksklusi adalah anak dengan epilepsi yang bebas kejang lebih dari 1 tahun, anak dengan palsi serebral, asma, penyakit jantung, hipertrofi adenotonsil dan diabetes melitus. Pengambilan subyek dilakukan secara consecutive sampling.

Orangtua pasien menjalani anamnesis dan diberi penjelasan secara rinci mengenai penelitian ini, serta mengisi informed consent secara lengkap. Semua subjek penelitian diberi kuesioner SDSC yang diisi oleh orang 
Riona Sari dkk: Gangguan tidur dengan epilepsi dan faktor yang memengaruhi

tua atau pengasuh berdasarkan riwayat pola tidur dalam 6 bulan terakhir. Setelah seluruh subyek penelitian mengisi kuesioner SDSC, masing-masing kuesioner dihitung skor total dari 26 pertanyaan dan masingmasing kategori gangguan tidur. Analisis statistik bivariat dilakukan dengan uji chi square dan Fisher dan dilanjutkan analisis multivariat dengan regresi logistik dengan metode stepwise untuk mengetahui faktor yang memengaruhi gangguan tidur pada anak dengan epilepsi.

\section{Hasil}

Didapat 147 subyek berusia 3-18 tahun yang telah terdiagnosis epilepsi selama periode penelitian. Di antara 147 subyek, 31 palsi serebral, 6 hipertrofi adenotonsil, 3 riwayat penyakit jantung, 2 riwayat asma, dan 12 telah bebas kejang lebih dari 1 tahun dieksklusi dari penelitian. Sembilan puluh tiga subyek yang eligible ikut serta dalam penelitian ini. Karakteristik subyek penelitian tertera pada Tabel 1.

Prevalensi gangguan tidur pada anak dengan epilepsi cukup tinggi, yaitu 67,7\%. Pada penelitian ini terdapat 3 dari 6 jenis gangguan tidur pada kuesioner SDSC. Empat puluh tiga $(63,2 \%)$ subyek mengalami jenis gangguan tidur memulai dan mempertahankan tidur paling tinggi, diikuti transisi tidur bangun $(23,8 \%)$, dan somnolen berlebihan (7,9\%). Tidak terdapat subyek yang mengalami gangguan pernapasan saat tidur, gangguan hiperhidrosis saat tidur.

Masing-masing jenis gangguan tidur dianalisis berdasarkan usia dan jenis kelamin (Tabel 2). Jenis kelamin laki-laki lebih banyak mengalami gangguan tidur dibandingkan perempuan, yaitu $24(55,82 \%)$ subyek gangguan memulai dan mempertahankan tidur, 10 (66,67\%) transisi tidur-bangun, dan 3 (60\%) gangguan somnolen berebihan. Berdasarkan kategori usia, hampir sama dengan sebaran karakteristik klinis pada anak dengan epilepsi pada populasi penelitian, terbanyak adalah usia sekolah (6-12 tahun) pada jenis gangguan memulai dan mempertahankan tidur $(39,54 \%)$ dan transisi tidur bangun $(53,33 \%)$.

Hasil analisis subgrup dan bivariat faktor yang berhubungan dengan gangguan tidur tertera pada Tabel 3. Berdasarkan jenis kejang, 43,8\% parsial dan $72,7 \%$ general mengalami gangguan tidur. Berdasarkan analisis bivariat dengan uji chi square terdapat hubungan bermakna pada anak dengan kejang general dengan
Tabel 1. Karakteristik dasar subyek penelitian $(\mathrm{n}=93)$

\begin{tabular}{llcc}
\hline & Karakteristik & \multicolumn{2}{c}{$(\%)$} \\
\hline Usia & Rerata $( \pm$ SB) $9,51( \pm 4,8)$ & & \\
\hline & Pra sekolah $(3-6$ tahun $)$ & 26 & $(28,0)$ \\
& Sekolah $(>6-12$ tahun $)$ & 35 & $(37,6)$ \\
& Remaja $(>12-18$ tahun $)$ & 32 & $(34,4)$ \\
Jenis kelamin & Laki laki & 53 & $(57)$ \\
& Perempuan & 40 & $(43)$ \\
Pendidikan & Tidak sekolah & 1 & $(1,1)$ \\
ibu & Pendidikan dasar & 39 & $(41,9)$ \\
& Pendidikan menengah & 36 & $(38,7)$ \\
& Pendidikan tinggi & 17 & $(18,3)$ \\
Onset & $\leq 3$ & 58 & $(62,4)$ \\
epilepsi & $>3$ & 35 & $(37,6)$ \\
(tahun) & & 18 & $(19,4)$ \\
Lama & $<1$ & 30 & $(32,3)$ \\
Pengobatan & $1-2$ & 24 & $(25,8)$ \\
(tahun) & $>2-5$ & 21 & $(22,6)$ \\
& $>5$ & 63 & $(67,7)$ \\
Jumlah OAE & Monoterapi & 30 & $(32,3)$ \\
& Politerapi & 16 & $(17,2)$ \\
Jenis kejang & Parsial & 77 & $(82,8)$ \\
& Umum & 5 & $(5,4)$ \\
Nama OAE & Fenobarbital & 9 & $(9,7)$ \\
& Fenitoin & 49 & $(52,7)$ \\
\hline & Valproat & &
\end{tabular}

gangguan tidur (nilai $\mathrm{p}=0,02$, OR 3,429, IK 1,13210,38). Anak dengan riwayat onset epilepsi pada usia kurang dari 3 tahun, 69\% mengalami gangguan tidur dibandingkan anak dengan riwayat onset epilepsi usia lebih dari 3 tahun, yaitu sebesar $65,7 \%$. Pada kelompok subyek anak dengan epilepsi yang menggunakan satu jenis obat (monoterapi) mengalami angka kejadian hampir sama dengan kelompok politerapi, yaitu 68,3\% vs $66,7 \%$. Angka kejadian gangguan tidur pada pasien yang mengonsumsi fenobarbital, fenitoin, dan valproat hampir sama. Onset epilepsi, jumlah dan jenis obat anti epilepsi fenobarbital, fenitoin dan valproat tidak terdapat hubungan secara statistik dengan gangguan tidur pada anak dengan epilepsi.

Dari analisis bivariat ini, semua variabel dimasukkan ke dalam analisis multivariat dengan menggunakan metode multivariate logistic regression (Tabel 4). Berdasarkan analisis multivariat diperoleh bahwa jenis kejang umum (general) meningkatkan risiko gangguan tidur 5,2 kali dibandingkan jenis kejang parsial (nilai $\mathrm{p}=0,024(\mathrm{p}<0,05)$, IK95\% 1,356-19,96). Berdasarkan analisis multivariat onset epilepsi, jumlah OAE dan jenis OAE (fenobarbital, fenitoin dan valproat) tidak bermakna secara signifikan memengaruhi kejadian 
Riona Sari dkk: Gangguan tidur dengan epilepsi dan faktor yang memengaruhi

Tabel 2. Jenis gangguan tidur berdasarkan usia dan jenis kelamin $(n=63)$

\begin{tabular}{|c|c|c|c|c|c|c|}
\hline \multirow{3}{*}{ Variabel } & \multicolumn{6}{|c|}{ Jenis gangguan tidur } \\
\hline & \multicolumn{2}{|c|}{$\begin{array}{l}\text { Memulai dan mempertahankan } \\
\text { tidur }\end{array}$} & \multicolumn{2}{|c|}{ Transisi tidur-bangun } & \multicolumn{2}{|c|}{ Somnolen berlebihan } \\
\hline & $\mathrm{n}$ & $\%$ & $\mathrm{n}$ & $\%$ & $\mathrm{n}$ & $\%$ \\
\hline \multicolumn{7}{|l|}{ Jenis kelamin } \\
\hline Laki-laki & 24 & 55,82 & 10 & 66,67 & 3 & 60 \\
\hline Perempuan & 19 & 44,18 & 5 & 33,33 & 2 & 40 \\
\hline \multicolumn{7}{|l|}{ Usia } \\
\hline Pra sekolah & 13 & 30,23 & 2 & 13,33 & 0 & 0 \\
\hline Sekolah & 17 & 39,54 & 8 & 53,33 & 2 & 40 \\
\hline Remaja & 13 & 30,23 & 5 & 33,34 & 3 & 60 \\
\hline
\end{tabular}

Tabel 3. Analisis bivariat faktor yang memengaruhi gangguan tidur (chi square dan Fisher*)

\begin{tabular}{|c|c|c|c|c|c|}
\hline Variabel & $\begin{array}{l}\text { Gangguan tidur } \\
(\mathrm{n}, \%)\end{array}$ & $\begin{array}{l}\text { Tidak gangguan } \\
\text { tidur }(\mathrm{n}, \%)\end{array}$ & Nilai p & OR & $\mathrm{IK}$ \\
\hline \multicolumn{6}{|l|}{ Jenis kejang } \\
\hline Umum & $56(72,7)$ & $21(27,3)$ & 0,024 & 3,429 & $1,132-10,36$ \\
\hline Parsial & $7(43,8)$ & $9(56,2)$ & & & \\
\hline \multicolumn{6}{|l|}{ Onset epilepsi (tahun) } \\
\hline$\leq 3$ & $23(65,7)$ & $12(34,3)$ & 0,820 & 0,863 & $0,353-2,106$ \\
\hline$>3$ & $40(69,0)$ & $18(31,0)$ & & & \\
\hline \multicolumn{6}{|l|}{ Jumlah OAE } \\
\hline Monoterapi & $43(68,3)$ & $20(31,7)$ & 0,878 & 0,075 & $0,426-2,714$ \\
\hline Politerapi & $20(66.7)$ & $10(33,3)$ & & & \\
\hline \multicolumn{6}{|l|}{ Jenis OAE } \\
\hline Fenobarbital* & $10(83,3)$ & $2(16,7)$ & 0,325 & 0,642 & $0,541-12,898$ \\
\hline Selain Fenobarbital & $53(65,4)$ & $28(34,6)$ & & & \\
\hline Fenitoin & $17(63,0)$ & $10(37,0)$ & 0,528 & 0,739 & $0,288-1,894$ \\
\hline Selain fenitoin & $46(69,7)$ & $20(30,3)$ & & & \\
\hline Valproat & $53(68,8)$ & $24(31,2)$ & 0,622 & 0,325 & $0,432-4,066$ \\
\hline Selain Valproat & $10(62,5)$ & $6(37,5)$ & & & \\
\hline
\end{tabular}

Tabel 4. Analisis multivariat faktor yang memengaruhi gangguan tidur

\begin{tabular}{lllll}
\hline \multirow{2}{*}{ Variabel } & \multicolumn{2}{c}{ Analisis bivariat } & \multicolumn{2}{c}{ Analisis multivariat } \\
\cline { 2 - 5 } & Nilai p & OR (IK95\%) & Nilai p & OR (IK95\%) \\
\hline Jenis kejang & 0,024 & $3,429(1,132-10,36)$ & 0,016 & $5,203(1,356-19.96)$ \\
Onset epilepsi & 0,820 & $0,863(0,353-2,106)$ & 0,653 & $0,801(0,440-17,85)$ \\
Jumlah OAE & 0,878 & $1,075(0,426-2,714)$ & 0,801 & $1,200(0,290-4,960)$ \\
Fenobarbital & 0,325 & $0,642(0,541-12,898)$ & 0,079 & $5,840(0,816-41,78)$ \\
Fenitoin & 0,528 & $0,739(0,288-1,894)$ & 0,546 & $1,635(0,332-8,064)$ \\
Valproat & 0,622 & $1,325(0,432-4,066)$ & 0,275 & $2,803(0,440-17,856)$ \\
\hline
\end{tabular}

Nilai $p<0,05$, bermakna secara statistik 
gangguan tidur pada anak dengan epilepsi.

\section{Pembahasan}

Epilepsi merupakan salah satu penyakit kronik yang menyebabkan gangguan kognitif, sosial, dan emosional pada anak. Meskipun gangguan tidur sering terjadi pada anak sehat, angka kejadiannya lebih tinggi pada anak dengan epilepsi. ${ }^{6,17,18}$

Hasil penelitian mendapatkan prevalensi gangguan tidur pada anak dengan epilepsi $67,7 \%$. Prevalensi ini lebih rendah dibandingkan penelitian Ong $\mathrm{dkk}^{21}$ $(73,7 \%)$ yang juga menggunakan kuesioner SDSC, tetapi terdapat perbedaan rentang usia subyek dan populasi yang digunakan. Pada penelitian ini gangguan tidur paling sering terjadi pada usia sekolah (77,2\%). Gangguan tidur pada anak sehat usia sekolah dipengaruhi aktifitas di sekolah, jam sekolah dan berbagai kegiatan di luar sekolah. Anak dengan epilepsi pada usia sekolah memiliki risiko yang lebih tinggi mengalami gangguan tidur. ${ }^{1}$

Jenis gangguan tidur terbanyak $(63,2 \%)$ adalah gangguan memulai dan mempertahankan tidur, diikuti transisi tidur-bangun $(23,8 \%)$, dan gangguan somnolen berlebihan (7,9\%). Gangguan memulai dan mempertahankan tidur ditentukan oleh lama tidur, peningkatan latensi tidur, dan gangguan pada tahapan tidur. Beberapa faktor yang diduga memengaruhi gangguan memulai dan mempertahankan tidur, yaitu konsumsi kafein dan nikotin, lingkungan, sleep hygiene dan co-sleeping. ${ }^{19}$

Jenis kejang umum (general) memengaruhi gangguan tidur berdasarkan analisis multivariat dengan regresi logistik, kejang umum meningkatkan risiko gangguan tidur 5,2 kali dibandingkan kejang parsial. Hasil ini serupa dengan penelitian Batista dan Nunes ${ }^{20}$ dengan metode potong lintang yang melaporkan bahwa kejang umum memiliki kejadian gangguan tidur dibandingkan kejang parsial. Hasil yang berbeda ditunjukkan pada penelitian sebelumnya, bahwa gangguan tidur pada anak epilepsi banyak terdapat pada tipe kejang parsial. ${ }^{6,8}$ Meskipun demikian, hubungan antara tipe kejang dengan gangguan tidur hingga saat ini masih belum jelas. ${ }^{15}$ Patofisiologi gangguan pelepasan GABA atau peningkatan asetilkolin dan norepinefrin bertanggung jawab atas terjadinya perubahan tahapan tidur pada anak dengan epilepsi.

Gangguan tidur dapat terjadi pada jenis kejang parsial dan umum. Berdasarkan epidemiologi, gangguan tidur paling sering terjadi pada tipe kejang parsial, terutama kelainan pada lobus temporal yang dikonfirmasi dengan pemeriksaan EEG. Akan tetapi, pada penelitian ini epilepsi tipe kejang parsial tidak dilakukan analisis berdasarkan pemeriksaan EEG sehingga tidak diketahui letak fokus epilepsi pada anak. Kejang umum lebih sering berhubungan dengan kebiasaan buruk saat tidur karena tipe kejang umum dapat menyebabkan gangguan kognitif dan memori dan dapat mengganggu gelombang lambat pada fase tidur. $^{20}$

Berdasarkan literatur, pada anak dengan onset epilepsi usia kurang dari 3 tahun sering dikaitkan dengan berbagai sindrom epilepsi pada anak, misalnya Lennox Gestaut syndrome, West syndrome dan Obtahara syndrome yang memiliki frekuensi kejang lebih sering dan sulit diatasi sehingga risiko terjadinya gangguan tidur lebih tinggi. Pada penelitian ini, gangguan tidur lebih sering dijumpai pada onset epilepsi kurang dari 3 tahun (69\%), tetapi onset epilepsi kurang dari 3 tahun tidak memengaruhi gangguan tidur pada anak dengan epilepsi.

Legros dan Bazil ${ }^{11}$ melaporkan bahwa obat anti epilepsi dapat menyebabkan perubahan arsitektur tidur. Pada penelitian ini berdasarkan jumlah obat, kejadian gangguan tidur sedikit lebih tinggi pada kelompok monoterapi dibandingkan politerapi ( $66,7 \%$ vs $68,3 \%)$ dan tidak ada perbedaan bermakna memengaruhi gangguan tidur. Berbeda dengan penelitian Batista dan Nunes, ${ }^{20}$ gangguan tidur lebih banyak dijumpai pada anak dengan epilepsi yang mengonsumsi obat lebih dari 1 jenis obat (politerapi). Pada kelompok monoterapi, hanya fenitoin, fenobarbital, valproat, dan karbamazepin. Karbamazepin tidak diikutkan dalam analisis karena hanya satu subyek sehingga tidak dapat dihitung secara bivariat. Pada golongan obat politerapi, oxcarbazepin, klobazam dan klonazepam juga tidak dapat dianalisis secara bivariat karena pada tempat penelitian ini, OAE tersebut tidak dikonsumsi sebagai obat tunggal (monoterapi).

Berdasarkan jenis obat anti epilepsi, fenobarbital lebih banyak menyebabkan gangguan tidur dibandingkan fenitoin dan valproat, tetapi tidak didapatkan perbedaan bermakna pada ketiga jenis obat tersebut. Peneliti hanya menggunakan tiga jenis obat anti epilepsi yang dikonsumsi pada subyek penelitian, tidak dapat dibedakan apakah ketiga jenis obat berdiri sendiri atau efek dari kombinasi obat tersebut. Fenobarbital 
merupakan obat anti epilepsi generasi pertama dengan mekanisme aksi peningkatan aliran ion klorida dengan memperpanjang pembukaan saluran yang diperantarai reseptor GABA. Fenobarbital menurunkan fase REM, latensi tidur dan sering terbangun akibat kejang yang memicu peningkatan fase NREM. ${ }^{22}$ Penelitian mengenai jenis obat anti epilepsi yang berhubungan dengan gangguan tidur masih sedikit. Beberapa penelitian lain, menunjukkan bahwa fenitoin dan valproat menyebabkan gangguan tidur dengan meningkatkan NREM fase 1, tetapi tidak terdapat perbedaan bermakna.

Beberapa kelemahan dalam penelitian ini, faktor lain yang berpengaruh seperti paparan kebisingan, sleep hygine, co sleeping, aktifitas, riwayat gangguan tidur sebelumnya, kepatuhan pengobatan dan pola pemberian obat anti epilepsi tidak ikut dianalisis. Kuesioner SDSC merupakan alat uji tapis (skrining) yang memiliki sensitivitas dan spesifitas yang cukup tinggi, tetapi kuesioner ini berdasarkan laporan orangtua sehingga dapat menyebabkan bias dan memengaruhi hasil penelitian. Penelitian ini merupakan penelitian pertama di Indonesia yang bertujuan untuk mengetahui prevalensi gangguan tidur pada anak dengan epilepsi dan faktor yang memengaruhi sehingga merupakan data awal yang dapat digunakan sebagai dasar untuk penelitian selanjutnya.

\section{Kesimpulan}

Prevalensi gangguan tidur pada anak dengan epilepsi cukup tinggi $(67,7 \%)$ dan terbanyak adalah jenis gangguan memulai dan mempertahankan tidur $(63,2 \%)$. Kejang umum (general) merupakan faktor yang memengaruhi gangguan tidur pada anak dengan epilepsi. Onset epilepsi, jumlah dan jenis obat anti epilepsi tidak memengaruhi gangguan tidur. Angka prevalensi gangguan tidur yang tinggi semakin meningkatkan morbiditas pada anak dengan epilepsi. Skrining awal dan tata laksana gangguan tidur yang tepat, terutama pada tipe kejang umum, dapat meningkatkan kualitas hidup dan menurunkan morbiditas anak dengan epilepsi.

\section{Daftar pustaka}

1. Owens J. Classification and epidemiology of childhood sleep disorders. Prim Care Clin Off Pr 2008;2:533-46.

2. Hysing M, Sy PD, Sivertsen B, Stormark KM, Elgen I,
Lundervold AJ. Sleep in children with chronic illness, and the relation to emotional and behavioral problems-a populationbased study. J Pediatr Psychol 2009;34:665-70.

3. Guerrini R. Epilepsy in children. Lancet 2006;367:499-524

4. Prilipko L, Saxena S, Boer H. Atlas: epilepsy care in the world. Buch 2005;129-91.

5. Ngugi AK, Bottomley C, Kleinschimdt I, Sander JW, Newton CR. Estimation of the burden of active and life-time epilepsy.

J Pediatr Child Health 2010;51:883-90

6. Wirrell E, Blackman M, Barlow K, Mah J, Hamiwka L. Sleep disturbances in children with epilepsy compared with their nearest-aged siblings. Dev Med Child Neurol 2005;47:754-9.

7. Yazdi Z, Sadeghniiat-Haghighi K, Naimian S, Zohal MA, Ghaniri M. Prevalence of sleep disorders and their effects on sleep quality in epileptic patients. Basic Clin Neurosci 2013; 4:36-41.

8. Byars AW, Byars KC, Johnson CS, Ton J, Fastenau PS, Perkins $S$, dkk. Epilepsy \& behavior the relationship between sleep problems and neuropsychological functioning in children with first recognized seizures. Epilepsy Behav 2008;13:607-13.

9. Al-Biltagi M. Childhood epilepsy and sleep. World J Clin Pediatr 2014;3:45-53.

10. Becker DA, Fennell EB, Carney PR. Daytime behavior and sleep disturbance in childhood epilepsy. Epilepsy Behav 2004;5:708-15.

11. Legros B, Bazil CW. Effects of antiepileptic drugs on sleep architecture: a pilot study. Sleep Med 2003;4:51-5.

12. Carter KA, Hathaway NE, Lettieri CF. Common sleep disorders in children. Am Fam Physician 2014;89:368-77.

13. Fricke-Oerkermann L, Plück, J, Schredl M, Heinz K, Mitschke A, Wiater A, Lehmkuhl G, 2007. Prevalence and course of sleep problems in childhood. Sleep 2007;30:1371-7.

14. Natalita C, Sekartini R, Pusponegoro H. Skala gangguan tidur untuk anak (SDSC) sebagai instrumen skrining gangguan tidur pada anak sekolah lanjutan tingkat pertama. Sari Pediatri 2011;12:365-72.

15. Gutter T, Brouwer OF, de Weerd AW. Subjective sleep disturbances in children with partial epilepsy and their effects on quality of life. Epilepsy Behav 2013;28:481-8.

16. Van Golde EGA, Gutter T, de Weerd AW. Sleep disturbances in people with epilepsy; prevalence, impact and treatment. Sleep Med Rev 2011;15:357-68.

17. Cortesi F, Giannotti F, Ottaviano S. Sleep problems and daytime behavior in childhood idiopathic epilepsy. Epilepsia 1999;40:1557-65.

18. Larson AM, Ryther RCC, Jennesson M, Geffrey AL, Bruno PL, Anagnos CJ, dkk. Impact of pediatric epilepsy on sleep patterns and behaviors in children and parents. Epilepsia 2012; 53:1162-9.

19. Cortese S, Ivanenko A, Ramtekkar U, Angriman, M. Sleep 
disorders in children and adolescents. Dalam: IACAPAP e-textbook of child and adolescent mental health. international association for child and adolescent psychiatry and allied professions. Geneva: IACAPAP; 2014.h.1-34.

20. Batista B, Nunes M. Evaluation of sleep habits in children with epilepsy. Epilepsy Behav 2007;11:60-6.
21. Ong LC, Yang WW, Wong SW, Al Siddiq F, Khu YS. Sleep habbits and disturbance in Malaysian children with epilepsy. J Paediatr Child Health 2010;46:80-4.

22. Placidi F, Scalise A, Marciani MG, Romigi A, Diomedi M, Gigli GL. Effect of antiepileptic drugs on sleep. Clin Neurophysiol 2000;2:115-9. 